\title{
DESAFIOS E RESPONSABILIDADES DAS HUMANIDADES DIGITAIS: PRESERVAR A MEMÓRIA, VALORIZAR O PATRIMÔNIO, PROMOVER E DISSEMINAR O CONHECIMENTO. O PROGRAMA MEMÓRIA PARA TODOS
}

Challenges and responsibilities of digital humanities: preserving memory, valuing heritage, promoting and disseminating knowledge. The Memory For All program

Retos y responsabilidades de las humanidades digitales: preservar la memoria, valorar el patrimonio, promover y difundir el conocimiento - el programa Memoria para Todos

MARIA FERNANDA ROLLO ${ }^{\mathrm{I}^{*}}$

DOI: http://dx.doi.org/10.1590/\$2178-149420200001000003

\footnotetext{
' Faculdade de Ciências Sociais e Humanas e Instituto de História Contemporânea da Universidade Nova de Lisboa, Portugal. (mffr@fcsh.unl.pt), ORCID ID: http://orcid.org/ 0000-0002-2249-7279 Ciência ID F91D-2B9A-5767.

*Professora associada da Faculdade de Ciências Sociais e Humanas da Universidade Nova de Lisboa e investigadora do Instituto de História Contemporânea.

Artigo recebido em $1^{\circ}$ de agosto de 2019 e aprovado para publicação em $1^{\circ}$ de agosto de 2019.
} 


\section{RESUMO}

Para que servem e por que existem as humanidades digitais? Não existem "digitais" associadas a outras áreas científicas. 0 que singulariza as humanidades digitais? Admitindo sua afirmação, salientam-se neste artigo seis eixos fundamentais por meio dos quais sua contribuição é mais evidente e relevante para a atividade científica e a sociedade em geral. 0 programa Memória para Todos, desenvolvido a partir do campo das humanidades, mas intrinsecamente multidisciplinar, utilizador intensivo de ferramentas digitais, convoca os eixos referidos, ilustrando as humanidades digitais para além da aplicação do digital na investigação na área científica das humanidades.

PALAVRAS-CHAVE: Humanidades digitais; Memória e patrimônio digital; Ciência aberta; Ciência cidadã; Comunidades e herança cultural; Investigação colaborativa.

\section{ABSTRACT}

Why do digital humanities exist and what are they for? There are no "digitals" associated with other scientific areas. What singularizes the digital humanities? By admitting this statement, this article highlights six fundamental axes through which the contribution of the digital humanities is most evident and relevant to scientific activity and society in general. The Memory for All program, developed from the humanities field but intrinsically multidisciplinary, intensive user of digital tools, summons the aforementioned axes, illustrating digital humanities beyond the application of digital in scientific research of the humanities field.

KeYwORDS: Digital humanities; Memory and digital heritage; Open science; Citizen science; Communities and cultural heritage; Collaborative research.

\section{RESUMEN}

¿Para qué son y por qué son las humanidades digitales? No hay "digitales" asociados con otras áreas científicas. ¿Qué singulariza a las humanidades digitales? Admitiendo su declaración, este artículo destaca seis ejes fundamentales a través de los cuales su contribución es más evidente y relevante para la actividad científica y la sociedad en general. El programa Memoria para Todos, desarrollado desde el campo de las humanidades, pero intrínsecamente multidisciplinario, usuario intensivo de herramientas digitales, convoca estos ejes, ilustrando las humanidades digitales más allá de la aplicación de lo digital en la investigación en el área científica de las humanidades.

PALABRAS ClaVE: Humanidades digitales; Memoria y patrimonio digital; Ciencia abierta; Ciencia ciudadana; Comunidades y patrimonio cultural; Investigación colaborativa. 
DESAFIOS E RESPONSABILIDADES DAS HUMANIDADES DIGITAIS: PRESERVAR A MEMÓRIA, VALORIZAR O PATRIMÔNIO, PROMOVER E DISSEMINAR O CONHECIMENTO. O PROGRAMA MEMÓRIA PARA TODOS

Dara que servem e por que existem as humanidades digitais? Não existem "digitais" asso-
ciadas a outras áreas científicas. O que singulariza as humanidades digitais?

Admitindo sua afirmação, salientam-se neste artigo seis eixos fundamentais (sem a pretensão de esgotar sua esfera de atuação) por meio dos quais a contribuição das humanidades digitais é mais evidente e relevante para a atividade científica e a sociedade em geral: salvaguarda e preservação do patrimônio digital; educação e formação; organização da informação; articulação com outras áreas científicas; acessibilidade, disseminação e partilha do conhecimento; compromisso com a sociedade.

Assume-se que as humanidades digitais, para além da evidente utilização de ferramentas digitais na área científica das humanidades e da adoção da componente do digital como objeto de investigação, podem/devem desempenhar funções relevantes em vários domínios, tomando-os como contribuição/responsabilidade perante a comunidade acadêmica/científica e a sociedade em geral.

Comete-se às humanidades digitais uma missão transversal de interface ou de contribuição ativa de intermediação, quer no nível da dinâmica científica, interdisciplinar, quer na relação com as comunidades e a sociedade.

A valorização, a preservação, a organização do patrimônio digital, abordadas neste artigo, constituindo uma área natural de atuação e singularização das humanidades digitais, em que convergem vários eixos, representam uma dimensão vital para o conhecimento e a salvaguarda da memória da humanidade.

O programa Memória para Todos, desenvolvido a partir do campo das humanidades, mas intrinsecamente multidisciplinar, utilizador intensivo de ferramentas digitais, convoca os eixos referidos, ilustrando as humanidades digitais para além da aplicação do digital na investigação na área científica das humanidades.

\section{NÃO IMPORTA EM QUE LÍNGUA E EM QUE PARTE DO MUNDO}

m 17 de outubro de 2003, a Organização das Nações Unidas para a Educação, a Ciência
e a Cultura (Unesco) adotou, na 32ª sessão da Conferência Geral, a Carta sobre a conservação do patrimônio digital.

Ficou, então, definido o que se entendia por patrimônio digital: recursos únicos nos domínios do conhecimento e da expressão humana, sejam eles de ordem cultural, educativa, científica e administrativa, ou que contenham informações técnicas, jurídicas, médicas ou de outros tipos, criadas digitalmente ou convertidas sob forma digital a partir de fontes analógicas 
existentes (<http://portal.unesco.org >). Acrescentava que os documentos digitais podiam revestir uma ampla e cada vez mais diversa gama de formatos eletrônicos, como textos, bases de dados, imagens fixas e animadas, documentos sonoros e gráficos, páginas web, sendo muitas vezes efêmeras, necessitando, por isso, de ações específicas de manutenção e de gestão desde sua criação.

Salientava-se ainda que esse patrimônio, não deixando de aumentar, podia existir em qualquer língua, qualquer parte do mundo, em qualquer domínio do conhecimento ou da expressão humana.

Ainda uma referência ao preâmbulo da Carta, dando nota de três aspectos essenciais: (i) o reconhecimento de como esses recursos em matéria de informação e expressão criadora, cada vez mais produzidos, difundidos, obtidos e conservados sob forma digital, estavam a criar um novo legado - o patrimônio digital; (ii) a consciência de que o acesso a esse patrimônio ofereceria maiores possibilidades à criação, comunicação e partilha do conhecimento entre todos os povos; e (iii) a compreensão de que esse patrimônio digital corria o risco de desaparecer e que sua conservação, no interesse das gerações presentes e futuras, era uma questão urgente, que interessava ao mundo inteiro.

Em síntese, era tempo de assumir que a "memória do mundo" passara também a ser digital.

Seis anos passados, em 2009, o diretor-geral da Unesco, Koïchiro Matsuura, enviou a todos os ministros encarregados das relações de cada Estado-membro com essa instituição (<https://unesdoc.unesco.org/ark:/48223/pf0000179529.page=2>) a mesma Carta sobre a conservação do patrimônio digital, chamando a atenção para a indispensabilidade de sua aplicação e recordando a responsabilidade de cada um - incluindo a própria Unesco, os Estados-membros, as organizações intergovernamentais e não governamentais internacionais, a sociedade civil e o setor privado.

A Carta evoca as questões essenciais que se apresentam hoje em dia. Ou, em outras palavras, refere-se a tudo, ou quase tudo. Desde logo, (i) a questão do acesso e da promoção da acessibilidade a esse patrimônio, em especial quando em domínio público, e a criação de condições adequadas que garantam a proteção contra qualquer forma de intrusão em matéria de informações sensíveis e pessoais; (ii) a indispensabilidade de encontrar um balanço adequado e sensato entre a salvaguarda dos direitos legítimos dos criadores e outros titulares de direitos e os interesses do público no que respeita ao acesso a esse patrimônio digital; (iii) a ameaça de perda para a posteridade que impera sobre esse patrimônio e as razões principais que o determinam, incluindo a obsolescência de equipamentos, a incerteza do financiamento, 
DESAFIOS E RESPONSABILIDADES DAS HUMANIDADES DIGITAIS: PRESERVAR A MEMÓRIA, VALORIZAR O PATRIMÔNIO, PROMOVER E DISSEMINAR O CONHECIMENTO. O PROGRAMA MEMÓRIA PARA TODOS

a inconsequência ou insuficiência das ações dos poderes públicos, nomeadamente em matéria de legislação; e (iv) também, talvez previamente, as atitudes das pessoas e das instituições. Atitudes que continuam a revelar-se, em muitos casos, resistentes ou incapazes de acompanhar a perceção da ameaça de perda e a própria evolução da tecnologia e das potencialidades e possibilidades que o patrimônio digital proporciona, nomeadamente no campo da investigação e para ampliar a criação e a difusão do conhecimento.

Por tudo isso, importava agir com urgência em 2003 e em 2009, e continua a ser imperativo agir hoje em dia.

Entretanto, muita coisa se alcançou, nomeadamente no campo e graças às humanidades digitais, mas muitíssimo permanece por alcançar.

A voragem avassaladora da revolução digital é implacável e imparável. Sobre ela mantenho, porém, a mesma serenidade e expectativa com que a história nos ensina a observar "revoluções" passadas, sem, porém, desconsiderar a amplitude e a velocidade de sua ação, potenciada pela tecnologia, pela disponibilidade cultural e mental (e também pelas suas resistências) e pela quase plenitude da globalização.

Daí resultam também a compreensão da volatilidade que impera em todos os domínios no tempo presente e a consciência de que a perda do patrimônio digital é demasiado rápida e inelutável, requerendo, para sustê-la, antecipação, estratégias, conhecimento, infraestruturas, enquadramento político, recursos financeiros e, não menos importante, consciência, empenho e envolvimento de todos os atores que integram o ecossistema, alargando-o, sem dúvida, à sociedade civil em geral.

Será esse, porventura, um dos desafios mais complexos e, simultaneamente, uma das responsabilidades mais prementes que hoje se apresentam às humanidades digitais: a salvaguarda da memória e a preservação e valorização do patrimônio digital em que, cada vez, mais se "corporiza". Complexo e premente porque, desde logo, trata-se de um patrimônio extraordinariamente vulnerável e relativamente ao qual nem sempre existe a noção de se tratar de um patrimônio. Além disso, a capacidade de atuação, seja no âmbito da consciencialização, seja no que respeita à adoção de medidas no sentido de sua preservação, transcende a comunidade das humanidades digitais, pressupõe a concertação com outas áreas científicas e disciplinares e requer apoios e infraestruturas adequadas que, inexoravelmente, exigem uma implicação institucional no nível do sistema científico e tecnológico e, em um nível mais lato, dos poderes e das políticas públicas.

Importa que sejam definidos enquadramentos jurídicos e técnicos adequados, elaborados com a colaboração dos diversos atores, que definam normas, procedimentos e boas prá- 
ticas. É ainda indispensável que se assegure a existência de sistemas fiáveis de preservação, desejavelmente no nível do sistema público, que garantam a autenticidade e a integridade da informação, bem como a indispensável seleção do que exige conservação permanente, sua preservação e curadoria e sua acessibilidade.

Se é válido em qualquer área, nesse caso é indispensável gerar uma rede de parcerias e cooperação adequada e em sintonia, sob pena da frustração do propósito da preservação digital, dadas sua abrangência, extensão e exigência técnica e de meios. Também por isso, se deve acrescentar a indispensabilidade da definição e a utilização de ferramentas adequadas de organização, classificação e partilha da informação, tendo sempre a consciência e, quanto a mim o propósito, de sua máxima acessibilidade. Não esquecendo, portanto, de que se trata de um patrimônio comum, virtualmente acessível a toda a humanidade. A organização do patrimônio digital, universalmente reconhecida e acessível, amplia e reforça o interesse do trabalho colaborativo e multidisciplinar, emergindo com cada vez maior premência e exigência, mas também possibilidades, o recurso a dinâmicas de trabalho relacionadas no plano da semântica, das ontologias e da própria acessibilidade, desde logo linguística.

Deve-se ainda salientar em que medida o patrimônio digital, integrando tudo o que ficou referido, requer um renovado papel das instituições que formam essa ampla galáxia do conhecimento - para além das instituições públicas nacionais/regionais/locais, que têm a missão da definição das políticas e das boas práticas; das instituições que tradicionalmente compõem o sistema de preservação e curadoria de informação, como arquivos e bibliotecas; e, de forma crescente, das instituições do sistema de ciência e tecnologia e de ensino superior. Seu envolvimento perspectiva-se em vários níveis, não só acrescentando e desenvolvendo conhecimento e proporcionando infraestruturas adequadas, mas no sentido de sua adaptação, que, na verdade, poderá pressupor sua transformação.

Dito de outra forma, arquivos e bibliotecas verão seus conteúdos cada vez mais transformados e acrescentados em suportes digitais, crescentemente diversificados, devendo, para o efeito, criar infraestruturas, formar pessoas (não só as que lá trabalham, mas seus utilizadores), ampliando suas funções, constituindo repositórios digitais, sob pena de serem substituídos por outras entidades ou de perderem parte do patrimônio cultural dos contextos que pretendem representar. As instituições de ciência, tecnologia e ensino superior (para além dos arquivos e das bibliotecas que integram) terão de operar no mesmo sentido, cumprindo-Ihes, porém, a missão de contribuir no plano científico e tecnológico e sobretudo no quadro da reflexão cultural e intelectual. Deve-se salientar que essa contribuição é indispensável no plano da organização da informação, e que essa missão transcende, cresce e amplia-se para tudo o que tem a ver com a produção do conhecimento. Voltaremos a essa questão, mas as instituições 
de ciência e tecnologia (em particular no nível dos centros de investigação), bem como as instituições de ensino superior, terão de assumir (e várias estão a fazê-lo) um papel cada mais determinante na acreditação, na organização e na intermediação da informação, para suas comunidades e para a sociedade em geral. À medida que a quantidade de informação disponível agiganta-se e generaliza-se, a missão dessas instituições torna-se mais premente e necessária.

As infraestruturas de investigação, em escala global e, nomeadamente na Europa (Esfri $<$ https://www.esfri.eu>), as que compõem os roteiros nacionais, bem como as diversas redes que se têm estruturado em nível global, internacional e nacional, podem participar dessa missão, estando-Ihes reservado um papel vital na organização e na gestão de dados de investigação. 0 aumento, inimaginável há poucos anos, de produção e disponibilização de dados de investigação e a indispensabilidade de sua preservação e organização ampliam e complexificam tudo quanto temos referido, em vários vetores, nomeadamente na associação de competências nos domínios da ciência e processamento e análise de dados. Não se pode deixar de sublinhar o grau de vulnerabilidade dessa informação digital e o processo de perda de que tem sido objeto, significando uma alienação grave do patrimônio digital, observado sob o ponto de vista cultural e científico, mas também econômico. Apenas como exemplo, no campo da ciência, Vines e outros autores (Vines et al., 2014) desenvolveram um estudo apontando para a perda de $80 \%$ dos dados dos artigos científicos nos próximos 20 anos, microrrealidade de um cenário muito maior de perda ou inacessibilidade de informação/patrimônio, mesmo se reversível pelo paradoxo da informação em buracos negros, de Stephen Hawking.

A perda não se extingue em si; ou seja, toda essa massa descomunal de informação digital tem um potencial de diálogo entre si e de criação de novo conhecimento, que importa alcançar no sentido de tornar o conhecimento realmente mais FAIR (findable, accessible, interoperable, reusable) e democratizado. E esse deve ser, a par de sua preservação, um dos propósitos a alcançar. Para tanto, para além das condições físicas, estando as tecnológicas disponíveis, terão de existir vontade e empenho político no nível dos diversos atores. Sublinhe-se que a conservação e a partilha dessa informação, organizada, expõem-na, desejavelmente, a um cada vez maior escrutínio, contribuindo para o combate à fraude, ao plágio ou a qualquer forma de transgressão e desrespeito pela propriedade intelectual.

\section{DESAFIOS E RESPONSABILIDADES DAS HUMANIDADES DIGITAIS}

s humanidades, em estreita associação com as ciências sociais, em especial, e com ou-
tras áreas disciplinares, têm em sua missão o estudo do patrimônio cultural, e cumpre- Ihes a formação das pessoas para seu conhecimento, valorização, salvaguarda e preservação. 
Têm, evidentemente, de incluir em seu âmbito a realidade digital, e assim o têm feito, refletindo parcial ou totalmente essa assunção nas designadas humanidades digitais.

Em que medida podem fazê-lo e qual a amplitude de sua ação tem sido sucessivamente questionado; daí, porventura, a profusão de definições que têm surgido e o amplíssimo debate, que continua na ordem do dia. ${ }^{1}$

Compreendendo sua indispensabilidade e a afirmação como uma prática, um ethos, tão transversal e generalizável quanto possível e necessário, é certo que as humanidades digitais terão de participar na construção e no desenvolvimento dos diversos contextos de sensibilização, consciencialização e formação nesses domínios. Começando pela educação/ formação básica, em que a perceção e a apetência das gerações mais jovens não significam, evidentemente, consciência de valorização e até respeito intelectual pela herança e pelo patrimônio digital (a que têm acesso natural e facilitado), compreensão formal e utilização de suas potencialidades/possibilidades ou, muito menos, necessidade de sua preservação. É certo, porém, que se está a instalar, de forma cada vez mais ampla, a indispensabilidade de aquisição e formação em matéria de competências digitais, bem como a noção de que as profissões do futuro as exigirão crescentemente. No nível do ensino superior e no campo das humanidades (e pode-se ampliar às artes e a vários domínios das ciências sociais), embora a formação em humanidades digitais (para simplificar) comece a fazer parte de alguns currículos, ela é ainda muito reduzida e sobretudo, em muitos casos, incompreendida pelos estudantes. Mais relevante, no campo da formação avançada, pós-graduada, a presença dessas áreas é ainda muito modesta. Mesmo começando a afirmar-se em alguns países como frequência possível ou obrigatória nos cursos de humanidades, a consciência dos alunos e professores é ainda limitada. Mais ainda, se considerarmos a comunidade de investigadores nas áreas das humanidades, o cenário surge agravado. Naturalmente, têm de se distinguir as diversas dimensões que as humanidades digitais compreendem/podem compreender, desde as competências para utilizar ferramentas disponíveis, pesquisar informação, organizar ou depositar conteúdos ou, em planos mais complexos, programar ou utilizar softwares de bases de dados, ou ferramentas de computação em seu todo. Mas, genericamente, com maior ou menor peso, as apetências e competências gerais no campo das humanidades digitais são escassas entre a própria comunidade das humanidades.

Entre outros aspectos, as humanidades digitais, como campo de conhecimento e atuação, e os profissionais associados às humanidades digitais, individualmente, em comunidade ou organizados institucionalmente, representam a melhor intermediação, pelo menos a mais disponível e apta, entre as humanidades e um mundo digital que se estende de forma cada 
DESAFIOS E RESPONSABILIDADES DAS HUMANIDADES DIGITAIS: PRESERVAR A MEMÓRIA, VALORIZAR O PATRIMÔNIO, PROMOVER E DISSEMINAR O CONHECIMENTO. O PROGRAMA MEMÓRIA PARA TODOS

vez mais inorgânica, sem fronteiras físicas e ajudando a esbater as barreiras culturais e linguísticas, e cujas coordenadas futuras porventura nem conseguimos imaginar.

Não será demais chamar a atenção para a importância dessa intermediação, logo no nível da valorização e da preservação do patrimônio digital, até porque os conteúdos digitais ou aquilo que deles perdurar tenderá a constituir, cada vez mais, seu objeto de estudo, diretamente ou porque seu suporte será digital. Importa ter presente que essa preservação, para que os conteúdos conservem sua integridade, acessibilidade e valor científico e patrimonial, para além do que foi já referido, decorre e só pode ser cumprida se abranger todo o seu ciclo de vida. É absolutamente essencial que as pessoas, e muito em particular os investigadores/ produtores de conhecimento, compreendam que a informação que estão a reunir e a produzir tem de ser cuidada desde que nasce.

Além disso, e essa perceção é intrínseca à comunidade científica das humanidades, o patrimônio digital tem de ser compreendido em escalas diversas, nomeadamente no nível das comunidades, coexistindo e requerendo práticas de conservação que transcendem os enunciados e os entendimentos das legislações nacionais ou das convenções internacionais e das boas práticas que adotam e recomendam. Acrescem o potencial e o alargamento de oportunidades que o digital proporciona no sentido da ampliação do universo de conteúdos, em especial imateriais, passível de ser registrado e preservado para as gerações vindouras. Ou seja, o digital aumenta a possibilidade de captar o legado cultural, significando que o patrimônio digital tende a aumentar exponencialmente. As pessoas, as comunidades estão cada vez mais a usar instrumentos, ferramentas, tecnologias digitais para registrar suas práticas e seus cotidianos, muitas vezes sem ter consciência de sua vulnerabilidade. Além disso, acrescenta-se a informação gerada a partir da interconexão que as liga, envolvendo novas formas de expressão e de comunicação (começando pela própria internet), em si mesmo patrimonializáveis. Nem tudo poderá/deverá ser preservado, mas, o que se quiser que perdure, terá de ser cuidado. Dentro do que se vislumbra, com a consciência das limitações no sentido de perspectivar o mundo futuro que a inteligência artificial tenderá a moldar, deve-se também assinalar o desenvolvimento de ferramentas que vão escalar as comunicações multilinguagem e multilíngua, o que replicará e aumentará ainda mais o patrimônio digital em escala global, abrangendo, desejavelmente, comunidades, regiões, contextos linguísticos atualmente em desvantagem ou marginalizados relativamente ao predomínio de algumas línguas, em especial o inglês.

Uma vez mais se convocam as humanidades e a aptidão das humanidades digitais no sentido da intermediação e da colaboração com outras áreas disciplinares e diferentes realidades tecnológicas. 
Sobrepõe-se, de qualquer forma, uma mudança cultural que tem de vingar, se quisermos garantir a preservação do patrimônio digital. A longevidade desse conhecimento, a perenidade desse legado dependem disso, e a comunidade acadêmica e científica não estará plenamente consciente dessa inexorabilidade. Por outro lado, o universo digital permite cada vez mais ampliar as possibilidades criativas e de produção de novo conhecimento, especialmente no campo das humanidades, se, uma vez mais, existirem enquadramento e infraestruturas e disponibilizar-se formação, aquisição de competências, acessibilidade e, como condição vital, se a comunidade 0 entender e quiser.

Em Portugal, têm-se afirmado várias dinâmicas, iniciativas, projetos, em qualquer uma das dinâmicas evocadas, embora, como referido, persista algum deficit em termos de conhecimento e utilização de recursos nos âmbitos disciplinares das humanidades. Embora com algum atraso e de forma mais lenta e titubeante, recuando à década de 80, a área das humanidades digitais tem se desenvolvido, procurando mesmo, sob contágio da realidade internacional, sua consagração disciplinar. À ação relativamente individual e voluntarista, em alguns casos internacionalmente atualizada, de alguns investigadores, mais ou menos enquadrados institucionalmente, sucede hoje em dia, pode-se dizer, uma comunidade organizada, com propósitos e objetivos comuns (Alves, 2016a: 91), tendo adquirido, entretanto, alguma formalização com a criação da linha temática Humanidades Digitais e Investigação Histórica, do Instituto de História Contemporânea (IHC) (<http://www.ihc.fcsh.unl.pt>), o Núcleo Património e Humanidades Digitais, da Universidade de Coimbra (<https://www.uc.pt/iii/ceis20/ grupos_investigacao/Grupo7>), e, no universo mais amplo da língua portuguesa, a fundação da Associação das Humanidades Digitais (<http://ahdig.org/>). Deve-se referir ainda a criação de infraestruturas de investigação especificamente dedicadas às ciências sociais, artes e humanidades (em particular o Rossio, <http://rossio.fcsh.unl.pt>), a participação portuguesa no Dariah e, mesmo, a recente criação do nó português da RDA - Research Data Alliance. Todos esses avanços são um sinal positivo, não significando, todavia, que as humanidades digitais estejam generalizadas no âmbito da comunidade acadêmica e científica das humanidades.

Em uma perspetiva que não é excessivamente otimista, é natural e expectável que a necessidade, a familiarização e a descoberta das possibilidades e do potencial que o mundo digital proporcionam acabem por se instalar, e que a pressão no sentido de sua formação e de sua procura venha a generalizar-se em ritmo mais acelerado. Porventura mais preocupante é que, antecipando esse cenário, mas podendo ocorrer ao mesmo tempo, persistam ou mesmo se instalem constrangimentos que impeçam o desenvolvimento das humanidades digitais. Veja-se 0 artigo de Osinski (2019), dedicado precisamente a identificar e alertar para as barreiras que existem no processo de formação e transformação de conhecimento científico na 
DESAFIOS E RESPONSABILIDADES DAS HUMANIDADES DIGITAIS: PRESERVAR A MEMÓRIA, VALORIZAR O PATRIMÔNIO, PROMOVER E DISSEMINAR O CONHECIMENTO. O PROGRAMA MEMÓRIA PARA TODOS

área das humanidades, chegando à conclusão de como a desconfiança e o deficit de interesse e competências no campo das humanidades digitais o condicionam. Em outro plano, e com outro tipo de abordagem, as conclusões a que se está a chegar no âmbito do projeto Desir a propósito da utilização da infraestrutura Dariah ${ }^{3}$ são também muito relevantes, apontando para uma utilização muito modesta dos recursos e das possibilidades que proporciona. A essa situação soma-se um potencial paradoxo: no inquérito desenvolvido, a percentagem de utilizadores de humanidades digitais é mais baixa nos investigadores com carreiras mais jovens. Na verdade, pode-se até falar de distanciamento da comunidade acadêmica/científica dessas infraestruturas, ou mesmo de desconhecimento de sua existência.

Ora, esse distanciamento opera em prejuízo do próprio desenvolvimento científico das humanidades. Em todo caso, para os que frequentam progressivamente os recursos disponíveis, o que se verifica, tal como em outras áreas científicas/disciplinares, é que os resultados são manifestamente positivos, devendo também acrescentar-se que as próprias dinâmicas associadas à produção e à partilha do conhecimento, seja no nível da formação, seja no nível da investigação, estão a atravessar um processo de profunda alteração. Dito de outra forma, a revolução digital, para simplificar, as humanidades digitais, para focar o campo específico das humanidades, estão a provocar e a ser acompanhadas de uma transformação no próprio processo de aprendizagem e de produção de conhecimento, alterando mesmo alguns de seus dogmas, pressupostos e paradigmas. ${ }^{4}$

\section{PRESERVAR A INFORMAÇÃO, PARTILHAR O CONHECIMENTO, DEMOCRATIZAR O ACESSO - CIÊNCIA ABERTA}

revolução digital tem composto uma oportunidade ímpar no sentido do alargamento
e da disseminação do patrimônio e da herança cultural compreendida em toda a sua amplitude. Além disso, o potencial que representa para o avanço do conhecimento, incluindo novas formas de aprendizagem e de participação da sociedade, e as possibilidades que proporciona no sentido de sua democratização são verdadeiramente impressionantes e porventura ainda aquém do que podemos captar/imaginar à luz do que a inteligência artificial permite perspectivar.

Mas, para tanto, é preciso que o acesso a essa realidade e o amplo conjunto de pressupostos que requer existam; se assim não for, em vez de oportunidade, poderá constituir um fator de afastamento, acentuar constrangimentos e contribuir para o agravamento das desigualdades de acesso ao conhecimento e à sua fruição. 
É indispensável a esta reflexão evocar a tendência, e as resistências que se têm apresentado, no sentido da promoção do acesso à ciência e à cultura, ou, se se quiser, ao conhecimento em geral. Antes de mais nada, cumpre não esquecer que estamos sempre perante um mundo em mudança acelerada, de amplitude dificilmente apreensível e mensurável, que não se esgota nas alterações no plano tecnológico; essa mudança contempla, reflete e arrasta importantes alterações no campo cultural, mental, social, político, econômico, ambiental... e estes estão também a atravessar processos de acentuada transformação.

No plano da ciência e do conhecimento, uma das tendências recentes, com potencial expressivamente transformador, reside no que genericamente podemos designar de "ciência aberta" - matéria em que, uma vez mais, encontramos um ponto fulcral de atuação das e para as humanidades digitais, alargando a interconexão das humanidades à sociedade.

\section{CIÊNCIA ABERTA}

atividade científica desenvolve-se em uma sociedade cada vez mais exigente relativa-
mente à responsabilidade das políticas, das instituições e mesmo dos cientistas, afirmando-se um contexto de acentuada vigilância pública referente tanto a grandes questões científicas, que colocam profundos dilemas éticos, quanto à supervisão da utilização de recursos públicos, acentuando-se quando nos reportamos a políticas e instituições públicas ou, como vimos, a um legado e patrimônio comuns.

São justamente crescentes as expectativas que a sociedade em geral e cada um de nós depositam na ciência (compreendendo todas as áreas disciplinares, incluindo o âmbito das humanidades), procurando ou mesmo requerendo, também por isso, enquadramentos institucionais e regulatórios e o recurso a instrumentos, como a avaliação, dedicados a promover, assegurar e dar conta desse cumprimento, mas também legitimar a afetação de recursos à investigação e à atividade científica, procurando satisfazer, e prestar contas, a um conjunto cada vez mais amplo de atores e forças para além da comunidade acadêmica e científica.

Essa dimensão colaborativa com a sociedade, com as comunidades pode ser determinante na construção de novo conhecimento e em sua preservação presente e futura, e mesmo instrumental na compreensão e na ampliação da utilização da realidade digital até no sentido da salvaguarda e da valorização do patrimônio cultural e digital, em geral e especificamente das comunidades. Para tanto, será essencial alguma extensão de formação e aquisição de competências e, sobretudo, a cumplicidade entre a academia/a comunidade do conhecimento "formal/científico" e as comunidades que compõem a sociedade em geral em um ambiente de responsabilidade patrimonial partilhada. 
DESAFIOS E RESPONSABILIDADES DAS HUMANIDADES DIGITAIS: PRESERVAR A MEMÓRIA, VALORIZAR O PATRIMÔNIO, PROMOVER E DISSEMINAR O CONHECIMENTO. O PROGRAMA MEMÓRIA PARA TODOS

Refiro-me ao ecossistema da ciência aberta em seu sentido mais amplo, ampliando-se, e é esse seu cerne, para além do sistema científico e tecnológico, na múltipla relação em que se encontra com os diversos parceiros e dinâmicas sociais e políticas, cruzando-se em todas as circunstâncias, com a afirmação da era digital em que se contextualiza. É que, para além das dimensões em que se desenvolve e concentra, acesso aberto, inovação aberta, ciência cidadã, entre outras, contempla-se precisamente o monumental desafio do arquivo/armazenamento, preservação, curadoria dos dados e informação digital que a sociedade produz em um ritmo e quantidade absolutamente inéditos, compondo o patrimônio digital. Vimos como é imperativo que se criem as condições indispensáveis à salvaguarda da produção científica nos moldes em que é gerada, cumprindo a responsabilidade histórica e civilizacional no plano da preservação e da valorização de nosso patrimônio e de nossa memória e herança cultural; é minha convicção que será mais provável cumprir esse desafio de forma colaborativa com a sociedade, compondo os argumentos deste artigo, com a cumplicidade ativa e a intermediação das humanidades digitais.

Se compreendermos a ciência aberta em sua dimensão holística, contemplando as diversas componentes e dinâmicas que a constituem/integram, então captaremos sua função fertilizante e regenerativa, e ela passará a ser uma aliada/ferramenta poderosa e ímpar, por sua capacidade, intrínseca, desinquietante e envolvente, de promover o conhecimento, sua partilha e apropriação social e, assim, sua perpetuação e perenidade.

A amplitude da ciência aberta, integrando e convocando os diversos parceiros sociais e a diversidade de sua rede colaborativa, confirma-a como ecossistema e afirma sua capacidade regenerativa, convidando-nos a falar em ciência circular — harmonizando um sistema persistente de renovação criadora, certamente de base científica, envolvendo as diversas comunidades, criando conhecimento com todos e para todos e garantindo sua sobrevivência e passagem para as gerações vindouras. A dimensão criativa é intrínseca à produção de conhecimento novo e à inovação, que em ecossistema de abertura convive com a participação da sociedade, cidadãos e instituições, e contribui para a preservação e a valorização da herança cultural, o reforço identitário e a construção de comunidade. Por fim, confirme-se o elogio da indispensabilidade de uma ciência/investigação responsável — social, científica, econômica e patrimonialmente responsável — apostada em contextos de preservação, transparência, reutilização, reprodutibilidade e valorização do conhecimento e da propriedade intelectual.

Entende-se a ciência aberta, em sintonia com o movimento global que tem advogado tornar a investigação científica, os resultados, os dados e sua disseminação ao alcance de todos, como um meio de promover a aproximação entre a ciência e a sociedade e a apropriação 
da ciência/conhecimento pela sociedade, constituindo simultaneamente um veículo e um catalisador para seu envolvimento direto (ciência cidadã, coprodução, coinovação... ), criando contextos de proximidade e evidência do recurso à ciência e estimulando sua apropriação por parte dos cidadãos e das instituições, para além do diálogo, que deve ser persistente, com as políticas públicas. Sua afirmação compreende, como pressuposto, a salvaguarda e a integridade da informação, organizada, como argumentado, de forma adequada e visando à máxima utilização e acessibilidade.

Salienta-se o percurso que tem acompanhado a afirmação da publicação em acesso aberto, os impulsos e as resistências, os jogos de interesse político, econômicos/comerciais e culturais, que têm composto a história recente e a tendência que se vislumbra no sentido da cada vez mais expressiva publicação em acesso aberto.

Na sequência do que ficou enunciado, resulta claro que entendemos que ciência aberta é mais do que a disponibilização em acesso aberto de dados e publicações; é a abertura do processo científico como um todo e uma nova forma de encarar o processo de produção e utilização do conhecimento.

Entende-se, assim, a defesa do argumento da atualidade da afirmação e até da centralidade que as humanidades digitais podem deter na conjuntura atual, bem como do contexto favorável de que se beneficia atualmente, desde logo por meio dos pilares que organizam a ciência aberta e na intermediação entre ciência/humanidades e sociedade.

\begin{tabular}{|l|}
\hline \multicolumn{1}{|c|}{ PILARES DA CIÊNCIA ABERTA } \\
\hline Acesso aberto: publicações e dados \\
- Repositórios | Diretórios de repositórios \\
- Infraestruturas partilhadas | Redes partilhadas \\
- Redes comuns | European Open Science Cloud; La Referencia \\
\hline Investigação aberta | Inovação aberta \\
\hline Conhecimento participado e colaborativo | Cocriação e coprodução \\
- Ciência cidadã \\
- Corresponsabilização \\
- Ciência para a sociedade
\end{tabular}

Fonte: <https://www.ciencia-aberta.pt>. 
DESAFIOS E RESPONSABILIDADES DAS HUMANIDADES DIGITAIS: PRESERVAR A MEMÓRIA, VALORIZAR O PATRIMÔNIO, PROMOVER E DISSEMINAR O CONHECIMENTO. O PROGRAMA MEMÓRIA PARA TODOS

A ciência aberta pressupõe, em suma, uma visão e um amplo compromisso político, social, econômico e cultural. Implica que se assumam mudanças, nos contextos de publicação e comunicação de ciência, nos modelos de avaliação científica e de financiamento da atividade científica, e, sobretudo, implica uma mudança cultural de todos os envolvidos no ecossistema científico e de produção do conhecimento.

A defesa do acesso aberto e da democratização do conhecimento tem um percurso histórico marcado por momentos e documentos fundamentais, prosseguindo seus propósitos universais, incluindo ação persistente das organizações internacionais, designadamente a Organização das Nações Unidas (ONU), a Organização para a Cooperação e o Desenvolvimento Econômico (OCDE), a Unesco ou a União Europeia. Mais recentemente, importa destacar a ação do comissário europeu para a investigação, inovação e ciência, Carlos Moedas, na promoção da ciência aberta, e o compromisso expresso do Conselho da União Europeia, em 2016, no qual os Estados-membros realizaram acordos relativos à ciência aberta. No caso de Portugal, o compromisso foi precisamente assumido no sentido da assunção de uma Política Nacional de Ciência Aberta (ver Resolução do Conselho de Ministros n 21/2016), propósito consagrado recentemente na lei da ciência, que constitui objeto do Decreto-lei n 63, de 16 de maio de 2019, e no qual se indica no artigo $8^{\circ}$ que: "As instituições de I\&D devem contribuir para uma ciência aberta, de acordo com as melhores práticas internacionais, garantindo 0 acesso livre e aberto do público ao conhecimento científico e promovendo o envolvimento e interação com a sociedade."

Vários países da América Latina, especialmente o Brasil, têm práticas enraizadas no campo da ciência cidadã e da ciência colaborativa e têm tido uma ação notável no âmbito do acesso aberto, ampliado, no nível de toda a região, por meio da rede de repositórios La Referencia (<http://www.lareferencia.info/pt/>), a que Portugal se associou recentemente. Portugal tem sido pioneiro no movimento de acesso aberto no plano internacional e, liderando-o em vários momentos, por meio de suas instituições de ensino superior, tem estado na linha da frente no que diz respeito à implementação de práticas de disponibilização de publicações científicas em acesso aberto, começando a introduzir referenciais e políticas/regulamentos institucionais desde o início da década de 2000. A disponibilização de publicações científicas em acesso aberto tem sido amplamente possibilitada pelo desenvolvimento de repositórios científicos (o primeiro datado de 2003), consolidados em torno do projeto Repositório Científico de Acesso Aberto de Portugal (RCAAP) (desde 2008) e de sua comunidade.

Os repositórios e as redes de repositórios são, hoje, determinantes para o desenvolvimento das diversas dinâmicas que temos evocado, bem como para o desenvolvimento de 
infraestruturas e redes de infraestruturas de investigação e outras ferramentas que permitem e potenciam a partilha de conhecimento em meio digital.

É sobre todas elas, divulgando e promovendo sua existência e utilização, que as humanidades digitais têm também de se debruçar, contribuindo mesmo no sentido de sua organização e classificação de conteúdos.

\section{INTELIGIBILIDADE}

E ntre os diversos eixos fundamentais de atuação das humanidades digitais, cumpre destacar uma dimensão cada vez mais vital, relativa à organização do próprio patrimônio digital, tal como tem sido evocado e pontuado ao longo do texto, mas que cumpre singularizar. As humanidades e, em seu papel específico e de intermediação, as humanidades digitais desempenham papel fundamental na concepção e na reflexão intelectual, bem como por meio de sua ação efetiva em todos os níveis, setores e vetores no plano da organização/inteligibilidade da informação, contribuindo efetivamente para sua condição FAIR. Refiro-me, entre outros aspectos, ao nível de formação, sensibilização, contribuição científica, desde a intervenção no plano das ciências documentais e de como estas terão também de se adaptar às exigências da realidade digital, da linguística, do conhecimento e da interpretação da cultura e sociedade, ou, é claro, na articulação com outras áreas científicas. Sua intervenção, com essa abrangência, terá de ir acontecendo, acompanhando ou, desejavelmente, antecipando a explosão em curso de produção de conteúdos digitais, que, sem inteligibilidade em sua organização, de pouco servirão à comunidade acadêmica e à sociedade em geral.

\section{CIÊNCIA E SOCIEDADE - RESPONSABILIDADE E COMPROMISSO}

or fim, uma dimensão essencial, em que as humanidades digitais ocupam lugar central,
ocorre no contexto já evocado das relações e interface entre ciência e sociedade e na compreensão intelectual e cultural de domínios em afirmação, como o da investigação responsável e inovação.

A investigação e os processos de inovação desenvolveram-se exponencialmente ao longo do século XX, acompanhando a necessidade e a tendência para a democratização do acesso ao conhecimento e de seus benefícios para a sociedade; em suma, para a melhoria da qualidade de vida das pessoas. 
DESAFIOS E RESPONSABILIDADES DAS HUMANIDADES DIGITAIS: PRESERVAR A MEMÓRIA, VALORIZAR O PATRIMÔNIO, PROMOVER E DISSEMINAR O CONHECIMENTO. O PROGRAMA MEMÓRIA PARA TODOS

Expressões como "responsabilidade social", "investigação responsável (RRI)", "public engagement", "investigação colaborativa", "cocriação" ou "ciência cidadã" constituem, hoje, uma evolução na forma como a ciência é pensada, criada, comunicada e apropriada.

Essa evolução tem cristalizado a distinção entre a criação do conhecimento, a compreensão e a utilização do conhecimento, e a divulgação e a comunicação do conhecimento.

Há, porém, uma convergência no sentido de incluir e integrar os diferentes atores sociais em contextos de participação ativa nos processos científicos e de inovação, de cocriação e intervenção cívica na definição de agendas de investigação, traduzindo, no fundo, a necessidade de articular e alinhar os processos e os resultados da ciência com as expectativas, as necessidades e os desafios da sociedade.

Essa visão tem sido promovida e desenvolvida, recentemente, no âmbito da Comissão Europeia, sobretudo plasmada no conceito de responsible research and innovation e na estratégia Horizonte 2020, em programas como o "Ciência com e para a Sociedade", mas que vai adquirindo também características únicas e autonomizando-se por meio de práticas e projetos de ciência cidadã ou de DIY Science, em que os cidadãos assumem o papel de cientistas, contribuindo ativamente em projetos científicos, nomeadamente pela recolha e análise de grandes quantidades de dados, com o objetivo de responder a problemas reais que decorrem da identificação de necessidades e desafios da própria sociedade.

Refira-se como todas essas dinâmicas têm sido possibilitadas e ampliadas a partir do desenvolvimento da realidade digital e como essas dinâmicas transformadoras no plano social e cultural constituem terreno e observação das humanidades.

De resto, será oportuno referir, na sequência do que se tem defendido, a indispensabilidade do envolvimento e a colaboração ativa das humanidades e das humanidades digitais na assunção da Agenda 2030, para a superação de qualquer um dos 17 Objetivos de Desenvolvimento Sustentável, ou, para um futuro próximo e mais específico ao enunciado da União Europeia para os próximos anos, na prossecução das cinco missões projetadas para o próximo Programa-Quadro de Investigação e Inovação - Horizonte Europa (Alterações Climáticas, Cancro, Oceanos, Cidades Inteligentes, Solo e Alimentação). Nenhuma das missões centra-se, especificamente, em tópicos dos universos científicos das ciências sociais, artes e humanidades, embora todas, de alguma forma, evoquem o interesse de sua presença, e a Missão das Alterações Climáticas afirme mesmo, em sua designação, incluir a transformação social. 


\section{MEMÓRIA PARA TODOS}

$\mathrm{O}$

programa Memória para Todos ${ }^{\circledR}$ (<https://memoriaparatodos.pt>) tem explorado algumas das possibilidades decorrentes do encontro entre as humanidades e os recursos digitais, sustentando e ilustrando simultaneamente o que se defendeu neste texto.

Memória para Todos é um programa de investigação empenhado na promoção do estudo, da organização e da disseminação do patrimônio histórico, cultural, tecnológico e digital relativo a Portugal, desenvolvido em estreita relação com arquivos e bibliotecas, instituições da administração pública, municípios e autarquias, entidades privadas, escolas e associações locais. Está institucionalmente enquadrado pela Faculdade de Ciências Sociais e Humanas da Universidade Nova de Lisboa, pelo Instituto de História Contemporânea e pelo Centro República. É, por natureza, um projeto colaborativo, sob a coordenação de uma equipe de investigação composta por Maria Fernanda Rollo, Maria Inês Queiroz, Filipe Silva, Inês Castaño, Luisa Seixas, contando com uma vasta equipe de colaboradores da academia e da sociedade em geral.

0 programa registra, preserva e partilha histórias e memórias, incluindo testemunhos orais, documentação e objetos pessoais e familiares, valorizando as histórias de vida e das comunidades.

Os conteúdos reunidos (como objetos, fotografias, testemunhos em áudio e vídeo, sons e outros registros), com a participação e o envolvimento dos cidadãos e das instituições, são disponibilizados online, em acesso aberto.

As primeiras ações realizadas remontam a 2009-2010, no âmbito das Comemorações para o Centenário da República, ${ }^{5}$ lançando o desafio à comunidade portuguesa para a partilha de memórias, testemunhos, objetos que retratassem a implantação da República em Portugal (5 de outubro de 1910) e a história da Primeira República (1910-1926), em efetivo ambiente de ciência cidadã. Foi, então, possível apreender a riqueza e a extensão de objetos, em especial de documentos e fotografias, que existiam na posse de particulares e, muito especialmente, a(s) memória(s) que perduravam entre herdeiros, familiares de pessoas que ainda viveram os acontecimentos de outubro de 1910 e nos anos seguintes. Ficou muito clara a relevância desses contributos para o aprofundamento e o enriquecimento da história do período da Primeira República. Importa assinalar que à Primeira República sucedeu, depois de um período de ditadura militar/nacional, o Estado Novo, e, como esse regime autoritário impôs um contexto de rejeição e censura da herança e do legado político e cultural do ideário e da prática republicanos, tornaram-se assim mais preciosos os testemunhos físicos que então 
DESAFIOS E RESPONSABILIDADES DAS HUMANIDADES DIGITAIS: PRESERVAR A MEMÓRIA, VALORIZAR O PATRIMÔNIO, PROMOVER E DISSEMINAR O CONHECIMENTO. O PROGRAMA MEMÓRIA PARA TODOS

"reapareceram". O legado dessa recolha, que ilustrou um conjunto muito vasto de exposições, publicações, vídeos, performances, foi partilhado com várias instituições e acolhido, virtualmente, pelo Centro República (<https://www.centrorepublica.pt>).

A partir de então, e especialmente a partir do projeto Portugal 1914 (a que já faremos referência mais detalhada), o programa formalizou-se e desenvolveu-se, assumindo como missão a recolha, a partilha e a preservação de memórias e testemunhos, a democratização do acesso às ferramentas da investigação histórica, a promoção de dinâmicas colaborativas de investigação, a produção e a disseminação de conhecimento e a criação de novas fontes para a investigação, centrando-se nas dinâmicas sociais da construção da memória como fator essencial para a definição de identidade. 0 programa Memória para Todos assume ainda, como propósitos, a promoção da educação patrimonial, a literacia e o desenvolvimento de competências digitais, e a democratização do acesso às ferramentas da investigação histórica.

Memória para Todos inclui, atualmente, um amplo conjunto de projetos, constituindo um programa interdisciplinar e colaborativo, distinguindo-se pelos métodos de envolvimento das comunidades, pela aplicação de diagnósticos e soluções de base científica sobre desafios sociais e pelo desenvolvimento de produtos em acesso aberto, partilháveis e reutilizáveis.

Nesse sentido, adota metodologias de registro, organização e divulgação de conteúdos específicos, de acordo com a natureza de materiais, suportes e informação em causa, nomeadamente testemunhos orais, histórias de vida, espólios e coleções privadas e familiares, por meio da criação de bases de dados e de processos digitais de conservação e disponibilização de dados. Convoca e aplica várias metodologias, associadas às ciências documentais, à história, à museologia, ao patrimônio, às ciências sociais em geral, devendo-se salientar as práticas de história oral, método biográfico, prosopografia, história local, georreferenciação, compondo um ambiente evidentemente comum e frequentado pelas humanidades digitais.

No desenvolvimento do programa, os cidadãos têm sido convidados a partilhar suas memórias pessoais e familiares relativas a determinados momentos e processos históricos e, em muitos casos, desafiados a envolver-se e a fazer parte ativa do programa; as comunidades têm sido convidadas e suscitadas no mesmo sentido, compreendendo e assumindo fazer parte e contribuir para a história de sua própria comunidade (ver, em particular, os projetos Memórias das Avenidas e Memórias das Aldeias).

Por tudo isso, e constituindo um programa de atividades, o Memória para Todos aplica também metodologias específicas de envolvimento comunitário, dinamização social e produção de conhecimento, tendo em vista o registro, a sistematização e o mapeamento de informação e dados provenientes da população em geral. 
O leque de metodologias convocadas é ainda mais amplo, correspondendo às especificidades de cada projeto, incluindo domínios menos afins às áreas das humanidades e das ciências sociais, nomeadamente no campo das ciências da vida.

Depreende-se sua natureza interdisciplinar e multidisciplinar, tanto no nível da concepção e do desenvolvimento do programa em geral quanto no do quadro específico de cada projeto que promove.

A dimensão multidisciplinar do programa amplia-se quando se trata de explorar os materiais recolhidos e, em outro plano, captam-se, acompanham-se e exploram-se os conteúdos, as relações e o enquadramento social em que se desenvolvem. Projetos como Memórias das Avenidas, Memórias de São Domingos, Memórias das Aldeias, entre outros, convocam as áreas das neurociências e da psicologia, especialmente a propósito do impacto da participação no programa Memória para Todos de pessoas/comunidades específicas.

\section{FAÇA HISTÓRIA PARTILHANDO A SUA}

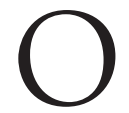

projeto Portugal 1914 (<www.portugal1914.org>) foi lançado em 2012, compreendendo um portal destinado a disponibilizar e a recolher informação sobre a história e o impacto do envolvimento português na Primeira Guerra Mundial. Incluiu várias atividades editoriais e exposições e uma forte componente de recolha de memórias e conteúdos, amplificada pelas redes sociais, e a organização de ações específicas de recolha de memórias, que passamos a designar de Dias da Memória (períodos específicos em que as pessoas são convidadas a deslocar-se a determinados locais para partilhar suas memórias e objetos associados e onde são recebidas por uma equipe composta por vários especialistas, estando presentes os recursos necessários para o registro de áudio e vídeo das entrevistas e a digitalização ou fotografia dos diversos materiais). A ação de recolha de memórias decorreu à escala nacional e virtualmente na França. Os primeiros Dias da Memória realizaram-se na Assembleia da República - Parlamento português, entre 17 e 19 de outubro de 2014, com a participação de dezenas de pessoas, cujas contribuições foram registradas em áudio e vídeo e os materiais que partilharam foram integralmente digitalizados ou fotografados. A descrição e a caracterização de todos esses conteúdos foram integradas em bases de dados relacionais. Seguiram-se iniciativas semelhantes em Tomar (fevereiro de 2015), Amadora (outubro de 2015), Vila Franca de Xira (setembro de 2016), continuando o interesse e o convite de vários municípios. Seus resultados integram o programa internacional Europeana 1914-1918. Terá sido a primeira iniciativa de crowdsourcing dessa envergadura realizada em Portugal, tendo contado com a colaboração de várias entidades e a divulgação pela televisão nacional, que elaborou 
um vídeo promocional apresentando pela primeira vez a consigna do programa Faça história partilhando a sua. 0 projeto foi um sucesso, pelo envolvimento que suscitou, pela dimensão, riqueza e diversidade do patrimônio reunido (todo ele reproduzido e uma parte, por solicitação de seus proprietários, doada a museus, arquivos e bibliotecas), e ainda sob o ponto de vista historiográfico, permitindo aprofundar o conhecimento sobre a história do envolvimento na Primeira Guerra nomeadamente pelo acesso a fontes até então inéditas. Envolveu uma vasta equipe de investigadores e de voluntários, em Portugal e na França. Além disso, promoveu a organização e a colaboração de várias escolas, bem como a participação de alunos, que desenvolveram projetos de recolha no âmbito de suas atividades escolares. 0 desenvolvimento de Portugal 1914 envolveu já o desenvolvimento de um conjunto de ferramentas digitais de gestão da recolha e organização e disponibilização da informação — bases de dados, edição de conteúdos, análise de informação.

A partir de então, são diversos os projetos realizados por iniciativa do programa ou por desafio de entidades. Destaquem-se, no contexto deste artigo, alguns aspectos que se relacionam ou se inscrevem no quadro geral das humanidades digitais, ou, dito de outra forma, o recurso às ferramentas digitais que têm acompanhado e, até de certa forma, contribuído para o desenvolvimento e a sucessiva superação de objetivos e desafios no âmbito do programa Memória para Todos.

Podemos, de certa forma, replicar o percurso deste artigo, começando por salientar o patrimônio digital existente ou constituído a partir da recolha de memórias e testemunhos, por meio do registro digital oral ou em vídeo, sua patrimonialização, registro, organização, edição, compondo um renovado legado, cuja salvaguarda e preservação cumpre garantir. A par desses testemunhos, a extensão, a diversidade e a riqueza de objetos associados, cujo registro, organização e reprodução digital se tem realizado. Tudo quanto se tem recolhido, incluindo a caracterização dos entrevistados, é registrado, descrito, classificado em bases de dados relacionais, acrescentando-se ferramentas de classificação e organização relacionando os registros em áudio e vídeo. Acrescente-se a articulação com a informação de contextualização recolhida, cumprindo preceitos e procedimentos rigorosos de classificação, adotando ontologias e semânticas normalizadas. 0 conjunto alargado de investigadores associados aos diversos projetos partilha um contexto de formação científica e técnica adquirida previamente ou no âmbito do programa em diversas áreas — bases de dados e edição digital, em particular. Em vários projetos, algum grau de formação ou aquisição de competências digitais envolve intervenientes externos ao programa — incluindo estudantes de escolas secundárias ou pessoas mais velhas e, em alguns casos, já aposentadas, como nos projetos Memórias das 
Avenidas ou Memórias de São Domingos. Qualquer um dos projetos pressupõe uma articulação dinâmica no nível da comunicação por meio digital.

Devem-se salientar também, constituindo um desafio permanentemente renovado e ampliado, as formas de colaboração a distância, por meio digital. Para além da submissão de conteúdos, mediante formulários específicos cada vez mais elaborados, como ocorre nessa fase com um dos projetos mais recentes, dedicado à recolha de testemunhos de emigrantes e de trabalhadores portugueses, assumiremos em breve o desafio de, na fase mais precoce possível, envolver a comunidade acadêmica, os investigadores que estudem temas semelhantes a participar em um cenário de investigação colaborativa.

Conforme referido, uma das condições essenciais do Memória para Todos é sua divulgação em acesso aberto e a promoção da máxima acessibilidade, respeitando rigorosamente 0 regulamento da proteção de dados e os princípios da propriedade intelectual, o que significa o esforço permanente de atualização e adaptação aos normativos/procedimentos que proporcionem sua integração e/ou interoperabilidade com um conjunto de plataformas, desde logo portais das entidades parceiras e infraestruturas mais ou menos especializadas. Todas as fases de desenvolvimento de qualquer um dos projetos, e o programa em geral, evocam cenários de multidisciplinaridade nas áreas de arquivística e ciências documentais em geral, informática, ciências da comunicação, design e o amplo conjunto de disciplinas diretamente associadas a projetos específicos.

Vários projetos focam conjunturas relevantes da história contemporânea de Portugal, e alguns, da iniciativa do Memória para Todos, têm sido desenvolvidos, como o Portugal 1914, com o apoio de entidades de âmbito nacional. Refiram-se o projeto dedicado às memórias da Revolução de Abril e da Descolonização (acompanhado pela RTP - Rádio e Televisão de Portugal e articulado com um programa editorial de quase duas centenas de episódios televisivos, organizando Dias da Memória no quartel histórico do Carmo, da Guarda Nacional Republicana) e o projeto Memórias da Resistência e da Liberdade, em articulação com o Museu do Aljube, recolhendo memórias e testemunhos de presos políticos durante o Estado Novo e, é esse nosso propósito mais recente, de seus familiares. Destaque-se, a propósito, uma das vertentes do programa, dedicada à promoção da utilização dos conteúdos recolhidos e organizados por parte da comunidade acadêmica e da sociedade em geral. Nesse caso, para além da contribuição para o conteúdo expositivo do Museu do Aljube, a disponibilização de informação para trabalhos de investigação, nomeadamente teses e dissertações acadêmicas, compondo o escopo de ferramentas digitais à sua disposição. 
DESAFIOS E RESPONSABILIDADES DAS HUMANIDADES DIGITAIS: PRESERVAR A MEMÓRIA, VALORIZAR O PATRIMÔNIO, PROMOVER E DISSEMINAR O CONHECIMENTO. O PROGRAMA MEMÓRIA PARA TODOS

Uma nota para referir o conjunto de projetos dedicados ao conhecimento e ao registro de memórias associadas ao mundo do trabalho - Memórias da Fábrica de Sacavém, da Cortadoria Nacional do Pelo, do Centro Fabril de São João da Madeira (envolvendo diversos setores de atividade), ente outros, e sua articulação com o novo projeto Europe at Work, a apresentar brevemente pela Europeana.

Alguns projetos têm tido como foco comunidades específicas, devendo-se destacar Memória das Avenidas, que conta com um grupo de colaboradores — os Maiores das Avenidas muitos dos quais moradores desse bairro histórico da cidade de Lisboa, tal como acontece com o projeto Memórias de São Domingos. Está em curso um projeto de recolha de Memórias das Aldeias, a propósito do qual cumpre salientar a intenção do projeto no sentido da contribuição, para além da identidade das comunidades, para a promoção e a valorização do desenvolvimento e da coesão social e territorial. Nesse caso, acrescenta-se ainda a disponibilidade de reutilização de conteúdos para enriquecer a promoção turística. Qualquer um desses projetos tem tido impacto social em outros domínios, incluindo as áreas da saúde, contribuindo para o combate às doenças da memória e ao isolamento ou o acompanhamento do envelhecimento ativo.

Por fim, cumprindo a missão definida e continuando com os objetivos apontados, os projetos que constituem o programa Memória para Todos decorrem da estratégia, do percurso de investigação e do compromisso social e científico prosseguidos. Assim, parte dos projetos mais recentes prossegue como propósito à contribuição para a Agenda 2030 e para a superação de um dos desafios societais mais complexos que hoje se apresentam à humanidade, associado às alterações climáticas. É nesse contexto que se enquadram projetos como o dedicado à Lagoa de Óbidos, ao Parque da Gorongosa em Moçambique, às reservas da biosfera, ou o projeto Living Rivers, procurando, a partir da recolha de memórias de tempos passados e das perceções que persistem, contribuir para o conhecimento e a consciencialização das alterações em curso.

0 compromisso do programa Memória para Todos é, em suma, baseando-se na prática científica, como é sua matriz, para com as pessoas e as comunidades e o contexto em que habitam, envolvendo-as em diversos planos e procurando uma dinâmica colaborativa que promova a preservação e a valorização da memória, a criatividade e a criação de novo conhecimento, garantindo sua partilha e promovendo sua acessibilidade, constituindo, portanto, uma interface e uma intermediação entre a academia e a sociedade.

0 recurso às ferramentas digitais acontece, natural e inevitável, procurado e desenvolvido, refletindo e apropriando-se do contexto digital pelas possibilidades que proporciona e pela forma como molda e condiciona a produção do conhecimento e a sociedade em geral, como oportunamente poderá ser percebido também por meio das Memórias do Digital. 


\section{CONCLUSÃO}

e é certo que a revolução digital é impiedosa e deixará para trás todos os que não se pre-
pararem, é também verdade que o desenvolvimento científico e tecnológico que a produziu e alimenta e as transformações sociais e culturais que a refletem terão de encontrar forma de conciliar e superar as diversas tensões que vão originando. Em todo caso, é imprescindível que se reflita, se definam caminhos e se estruturem estratégias, que deverão ser, a benefício de seu sucesso, cada vez mais colaborativas e contar com o empenho e a responsabilidade dos diversos atores - incluindo os responsáveis pelas políticas públicas e pela criação de estruturas adequadas aos cientistas e cidadãos em geral.

As humanidades digitais têm um papel a desempenhar, no nível das humanidades, da comunidade científica e nas diversas interconexões que podem potenciar. Parece-me imperativo que as humanidades persistam na renovação de suas dinâmicas metodológicas e mesmo epistemológicas, no sentido de se adaptarem às mudanças em curso, contribuindo, em particular, para a reflexão e a interpretação da transformação dos próprios processos de aprendizagem e de investigação, compreendendo sua relação com as comunidades e uma sociedade em que a realidade digital é cada vez mais dominante.

A afirmação das humanidades digitais tem ocorrido sem a indispensabilidade de sua formalização ou institucionalização disciplinar, servindo aos investigadores e às diversas comunidades. A presença das humanidades digitais em determinadas esferas, eixos de atuação, como os salientados, tem se revelado muito positiva, acentuando a relevância e até singularidade de sua contribuição.

Programas como o Memória para Todos, projetos como os que o integram, refletem de forma muito expressiva a importância e as possibilidades que o recurso a ferramentas digitais ou às humanidades digitais proporciona. Programas dessa natureza podem realmente ser determinantes e inspiradores para a promoção do conhecimento a partir das humanidades, mas em ambiente de multidisciplinaridade, assumindo um claro compromisso com a sociedade e a sustentabilidade. Será porventura altura de incluir no escopo de suas próximas ações a captação e o registro da(s) Memória(s) da Sociedade Digital. 
DESAFIOS E RESPONSABILIDADES DAS HUMANIDADES DIGITAIS: PRESERVAR A MEMÓRIA, VALORIZAR O PATRIMÔNIO, PROMOVER E DISSEMINAR O CONHECIMENTO. O PROGRAMA MEMÓRIA PARA TODOS

\section{NOTAS}

1 Não abordo ou desenvolvo, nem é propósito deste artigo, a definição de humanidades digitais ou a ampla problemática e profusão de questões que suscita. Existe uma vasta e atualizada bibliografia disponível sobre o tópico, devendo-se destacar, pela consagração da temática, Susan Schreibman, Ray Siemens e John Unsworth ([Ed.] Companion to digital humanities. Oxford: Blackwell, 2004). Dever-se-á ver, pela pertinência das questões que apresenta e pelo conjunto de referências que contempla, o recente artigo de Osiski (2019).

20 projeto Desir desenvolveu-se nos últimos três anos com o objetivo de reforçar a sustentabilidade do Dariah, estabelecendo-o como um parceiro fundamental junto das comunidades acadêmicas, em particular das artes e humanidades. 0 consórcio Desir é composto por vários membros do Dariah, por representantes dos futuros membros e por especialistas externos, tendo sido desenvolvidos esforços para a inclusão de um conjunto amplo de países, de modo a conferir-lhe uma escala verdadeiramente europeia. Portugal é representado pela Faculdade de Ciências Sociais e Humanas da Universidade Nova de Lisboa — Maria Fernanda Rollo (coord.), Maria Inês Queiroz, Inês Castaño, Rosário Jorge, João Fernandes, Filipe Silva —, liderando a work package que trabalha a dimensão da confiança e a fiabilidade da infraestrutura, tendo como objetivo principal propor recomendações para seu desenvolvimento sustentável.

3 Dariah (Digital Research Infrastructure for Arts and Humanities) (<https://www.dariah.eu>) foi criado como uma rede e uma infraestrutura pan-europeia. Em 2014, após sua expansão e consolidação, que envolveu a inclusão do Dariah no roteiro Esfri, essa infraestrutura tornou-se uma Eric (European Research Infrastructure Consortium).

4 Veja-se o projeto Time Machine, financiado pela Comissão Europeia (<https://actu.epfl.ch/news/unleashing-big-data-of-the-past-europe-builds-a-ti/>).

5 A Comissão para as Comemorações do Centenário da República foi nomeada pelo presidente da República com a seguinte composição: Artur Santos Silva (presidente), Maria Fernanda Rollo (comissária executiva), Francisco Sarsfield Cabral, Raquel Henriques da Silva e João Serra, substituído por Rui Vieira Nery.

\section{REFERÊNCIAS BIBLIOGRÁFICAS}

ALVES, D. As humanidades digitais como uma comunidade de práticas dentro do formalismo académico: dos exemplos internacionais ao caso português. Ler História, n. 69, p. 91-103, 2016 a.

Humanidades digitais e investigação histórica em Portugal: perspectiva e discurso (1979-1915). Práticas da História, v. 1, n. 2, p. 89-116, 2016b.

OSINSKI, Z. Information infrastructure of contemporary humanities and the digital humanities development as a cause of creating new information barriers: a Polish case. Digital Scholarship in the Humanities, v. 34, n. 2, p. 386-400, jun. 2019.

ROLLO, M. F. Conhecimento para o desenvolvimento: ciência em português para um mundo global. In: CONFLUÊNCIAS DE CULTURAS NO MUNDO LUSÓFONO. XXVII ENCONTRO DA ASSOCIAÇÃO DAS UNIVERSIDADES DE LÍNGUA PORTUGUESA, 2017, Campinas. Anais... Campinas, 2017. p. 27-34.

Partilhar conhecimento: do acesso aberto à ciência aberta. Para a prosperidade e o desenvolvimento. In: CARVALHO, M. (Org.). Acesso aberto: da visão à ação. Contextos, cenários e práticas. Lisboa. Universidade Aberta. 2018. p. 1-8. 
. Open Science - Sharing Knowledge, Building Democracy, Science Fórum, december 2016.

SILVA, F.; CASTAÑO, I.; QUEIROZ, I.; SEIXAS, L.; ROLLO, M. F. Memory from the Avenues: a collaborative strategy towards local history and heritage. Memoria Media Review, n. 3, art. 8, 2018.

VINES, T. H. et al. The availability of research data declines rapidly with article age. Current Biology, n. 24, p. 94-97, 6 jan. 2014. 